\title{
Microstructural Evolution of Ti-Mo-Ni-C Powder by Mechanical Alloying
}

\author{
Hiroyuki Hosokawa, Kiyotaka Kato, Koji Shimojima and Akihiro Matsumoto \\ Materials Research Institute for Sustainable Development, National Institute of Advanced Industrial Science and Technology, \\ Nagoya 463-8560, Japan
}

The microstructural evolution of (Ti,Mo)C-Ni powder by mechanical alloying of pure titanium, nickel, carbon and molybdenum as starting powder with the composition of TiC-20 $\mathrm{Mo}_{2} \mathrm{C}-20 \mathrm{Ni}$ in mass $\%$ were investigated by X-ray diffraction (XRD) using CuK $\alpha$ radiation, field emission scanning electron microscopy (FE-SEM) with energy-dispersive X-ray spectroscopy (EDS), and transmission electron microscopy (TEM) with EDS. The powders were mixed gradually and the size of the mechanically alloyed particles was of sub-micrometer order. The TiC structure, which indicated smaller lattice constant than $\mathrm{TiC}$, clearly appeared after $100 \mathrm{~h}$ milling time. The particles consisted of fine grains of about $5 \mathrm{~nm}$ size. The nickel was transformed from crystallized phase into an amorphous phase by mechanical alloying. The molybdenum was dissolved into TiC structure and Mo/Ti ratio in (Ti,Mo)C was about 3/7. [doi:10.2320/matertrans.MRA2008280]

(Received August 27, 2008; Accepted October 15, 2008; Published December 3, 2008)

Keywords: TiC, mechanical alloying, molybdenum, microstructure

\section{Introduction}

TiC based cermets have attracted a great deal of attention because of their high strength, high hardness, and their good chemical and thermal stability. Finer and modified hard phases as well as modified binder phases have been main focus of attention among the researchers, in order to improve toughness and wear resistance of their materials. ${ }^{1-11)}$ As far as refinement of hard phase is concerned, mechanical alloying is one of the effective methods to produce the finer TiC grain size than the conventional method. ${ }^{11,12)}$

It is well known that one of the main disadvantage of TiC based cermets is wettability between $\mathrm{TiC}$ and binder materials. Molybdenum can be added in order to improve this, because molybdenum increases the wetting of $\mathrm{TiC}$ by $\mathrm{Ni}$ binder and finer hard phase. ${ }^{1-3)}$ There have been reported about TiC based cermet containing $\mathrm{Mo}$ and $\mathrm{Mo}_{2} \mathrm{C} .{ }^{1-3,5-8,10,12)}$

Focusing on microstructures in $\mathrm{TiC}$ based cermet containing $\mathrm{Mo}$ and $\mathrm{Mo}_{2} \mathrm{C}$, in general, they have a core-rim structure, that is, a (Ti,Mo)C rim surrounding a TiC core. ${ }^{13)}$ However, Kim et al. reported that nano-particle ( $\mathrm{Ti}, \mathrm{Mo}) \mathrm{C}-\mathrm{Ni}$ cermets without a core-rim structure have been synthesized by mechanical alloying, having high hardness of $92 \mathrm{HR}_{\mathrm{A}}{ }^{12)}$

To date, to the author's knowledge, there is no detailed information about the microstructural evolution of Ti-Mo$\mathrm{Ni}-\mathrm{C}$ into $(\mathrm{Ti}, \mathrm{Mo}) \mathrm{C}-\mathrm{Ni}$ powder by ball milling. The purpose of this work is to investigate the change of morphologies, chemical components, and microstructures for Ti-Mo-Ni-C powder into $(\mathrm{Ti}, \mathrm{Mo}) \mathrm{C}-\mathrm{Ni}$ in order to better understand it.

\section{Experimental Procedures}

The powders used in this work were $99.9 \% \mathrm{Ti}$ with $45 \mu \mathrm{m}$, $99.9 \% \mathrm{C}$ with $20 \mu \mathrm{m},>99.9 \% \mathrm{Ni}$ with $5 \mu \mathrm{m}$, and $>99.9 \% \mathrm{Mo}$ with $3 \mu \mathrm{m}$. A powder mixture having a composition of TiC$20 \mathrm{Mo}_{2} \mathrm{C}-20 \mathrm{Ni}$ in mass\% was prepared. The powders were dry mixed together with $\mathrm{WC} / \mathrm{Co}$ balls into a $500 \mathrm{ml}$ hardened steel pot with an O-ring seal under $667 \mathrm{KPa}$ of $\mathrm{Ar}$ atmosphere. A planetary ball mill (Fritsch Pulverisette 5) was used for durations of up to $700 \mathrm{~h}$. The ball-to-powder weight ratio (BPR) was fixed at $20: 1$.
The powders were milled for various times, and were then analyzed to determine the change of the phase compositions and morphologies by means of X-ray diffraction using $\mathrm{CuK} \alpha$ radiation, field emission scanning electron microscopy (FE-SEM) with energy-dispersive X-ray spectroscopy (EDS), and transmission electron microscopy (TEM) with EDS. The crystallite size of the TiC structure for powder after $700 \mathrm{~h}$ milling was estimated, based on the half-width of the X-ray diffraction pattern of the specimen using Scherrer's formula. The powders for FE-SEM with EDS observation were embedded in polymer and $\mathrm{Cu}$ powders for conductivity and then were mechanically polished. The lattice constants for the powder and the sintered compact were estimated by means of selected area diffraction pattern (SADP).

The as-synthesized powders after $700 \mathrm{~h}$ milling time were pressed into pellets under $100 \mathrm{MPa}$ to pellets. These green pellets were then sintered at $1723 \mathrm{~K}$ for $1 \mathrm{~h}$ under vacuum. The sintered compact was also analyzed by X-ray diffraction, FE-SEM and TEM-EDS.

\section{Results and Discussion}

The XRD patterns of the milled powders for different times are shown in Fig. 1. Peaks of crystalline titanium,

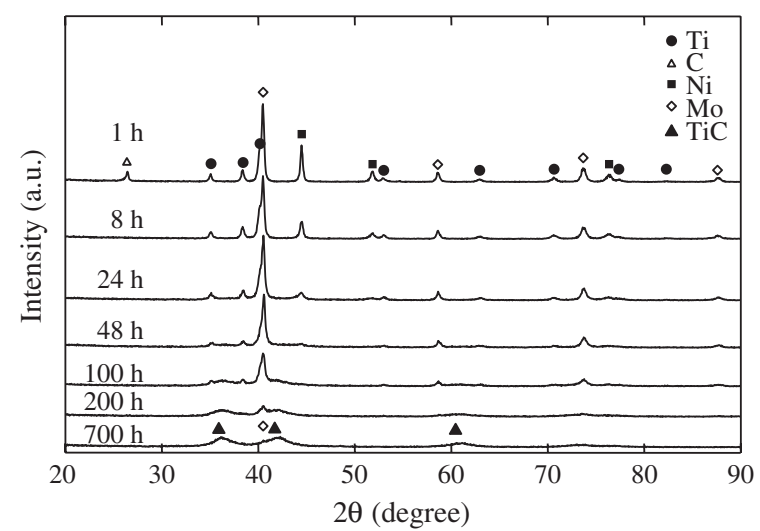

Fig. 1 XRD patterns for the milled Ti-Mo-Ni-C powders with different milling times. 

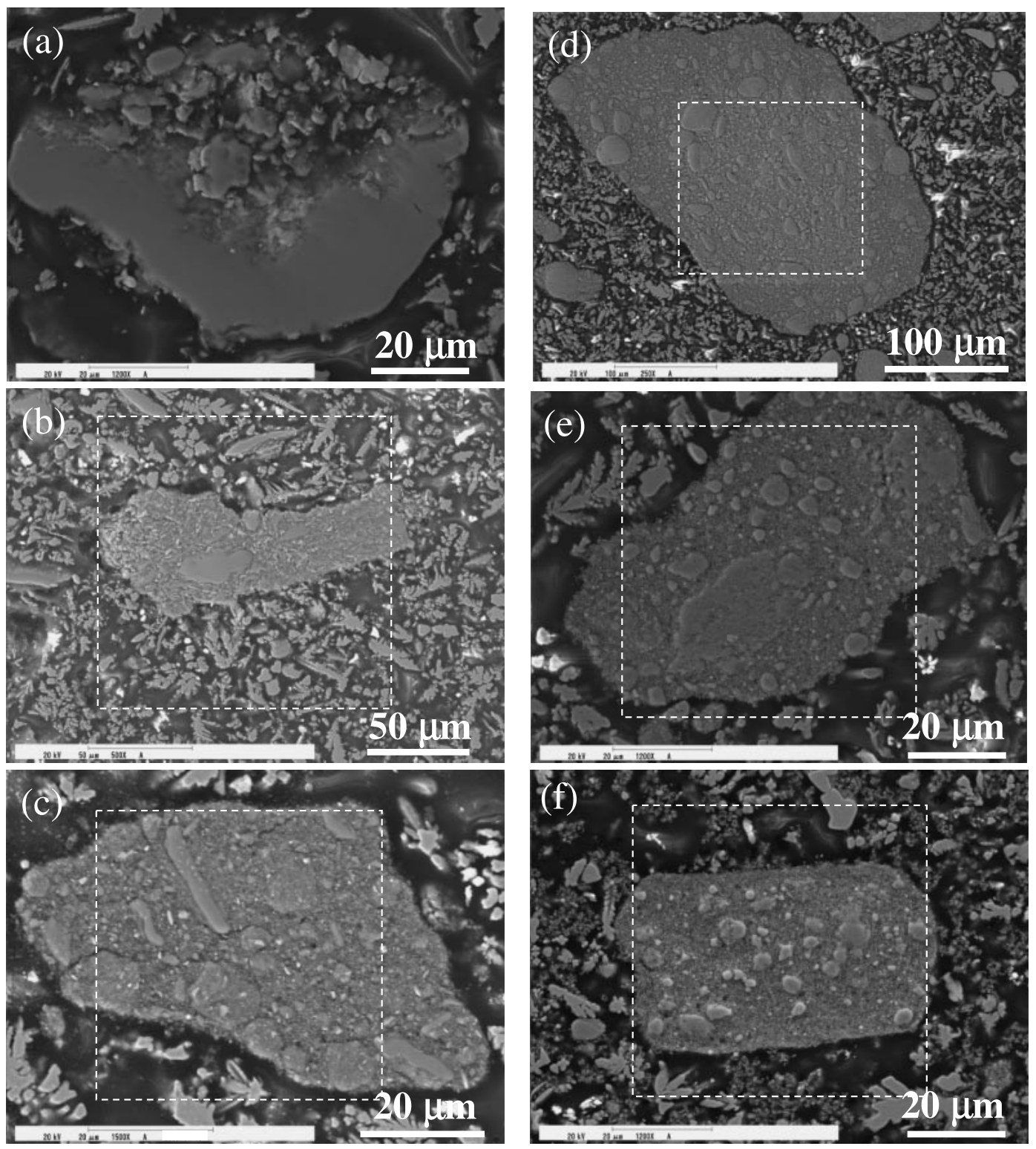

Fig. 2 SEM photographs of the powders for (a) $1 \mathrm{~h}$ milling time, (b) $8 \mathrm{~h}$ milling time, (c) $48 \mathrm{~h}$ milling time, (d) $100 \mathrm{~h}$ milling time, (e) $200 \mathrm{~h}$ milling time and (f) $700 \mathrm{~h}$ milling time. The framed parts by the dashed lines are the regions for EDS mapping images in Fig. 4 .

carbon, molybdenum and nickel clearly existed and were sharp after $1 \mathrm{~h}$ milling. However, the peaks gradually became broader with increasing milling time, indicating that the grains became finer with an increase in milling time. The carbon peak and the nickel peaks disappeared after $8 \mathrm{~h}$ and $100 \mathrm{~h}$ milling time, respectively. After $200 \mathrm{~h}$ milling, a new crystalline phase having a TiC structure clearly appeared. It is known that the milling of $\mathrm{Ti}$ and $\mathrm{C}$ synthesizes $\mathrm{TiC}$ through ball milling. ${ }^{11)}$ Therefore, it is considered that these powders were reacted as a $\mathrm{TiC}$ structure. The peaks of the $\mathrm{TiC}$ structure in this work showed a trend toward higher angles, compared with TiC peaks. This trend is the same as $(\mathrm{Ti}, \mathrm{Mo}) \mathrm{C}$ reported by Kim et al. ${ }^{12)}$ After $700 \mathrm{~h}$ milling time, the Ti and Mo peaks finally disappeared. The peaks of the TiC structure were broad after $700 \mathrm{~h}$ milling time, indicating that a fine crystallite size for TiC structure is achieved by ball milling. The grain size for it was estimated to be about $4 \mathrm{~nm}$, applying Scherrer's formula to half-width.
SEM photographs of the powders for various milling times are shown in Figs. 2 and 3. While powders agglutinated after $8 \mathrm{~h}$ milling time, the boundaries between the starting powders were clear. After $48 \mathrm{~h}$ milling time or longer, some parts of the aggregates had insufficient milled regions, and other parts had sub-micrometer particles (see Fig. 3(a)). The ratio of the regions consisting of particles with sub-micrometers increased along with an increase in milling time. After $200 \mathrm{~h}$ milling, almost all regions consisted of sub-micrometer particles, with a few white regions having particles of several micrometers (see Fig. 3(b)). After $700 \mathrm{~h}$ milling time, almost all particles were sub-micrometers (see Fig. 3(c)), despite the $4 \mathrm{~nm}$ or so as calculated by Scherrer's formula. It is speculated that the particle consists of nm-scale grains.

EDS mapping images of the powders for various milling times are shown in Fig. 4. There were clearly the regions for each element in aggregate after $1 \mathrm{~h}$ milling time. In particular, the Ti region was larger due to a larger starting powder diameter. The high concentrated regions of each element 

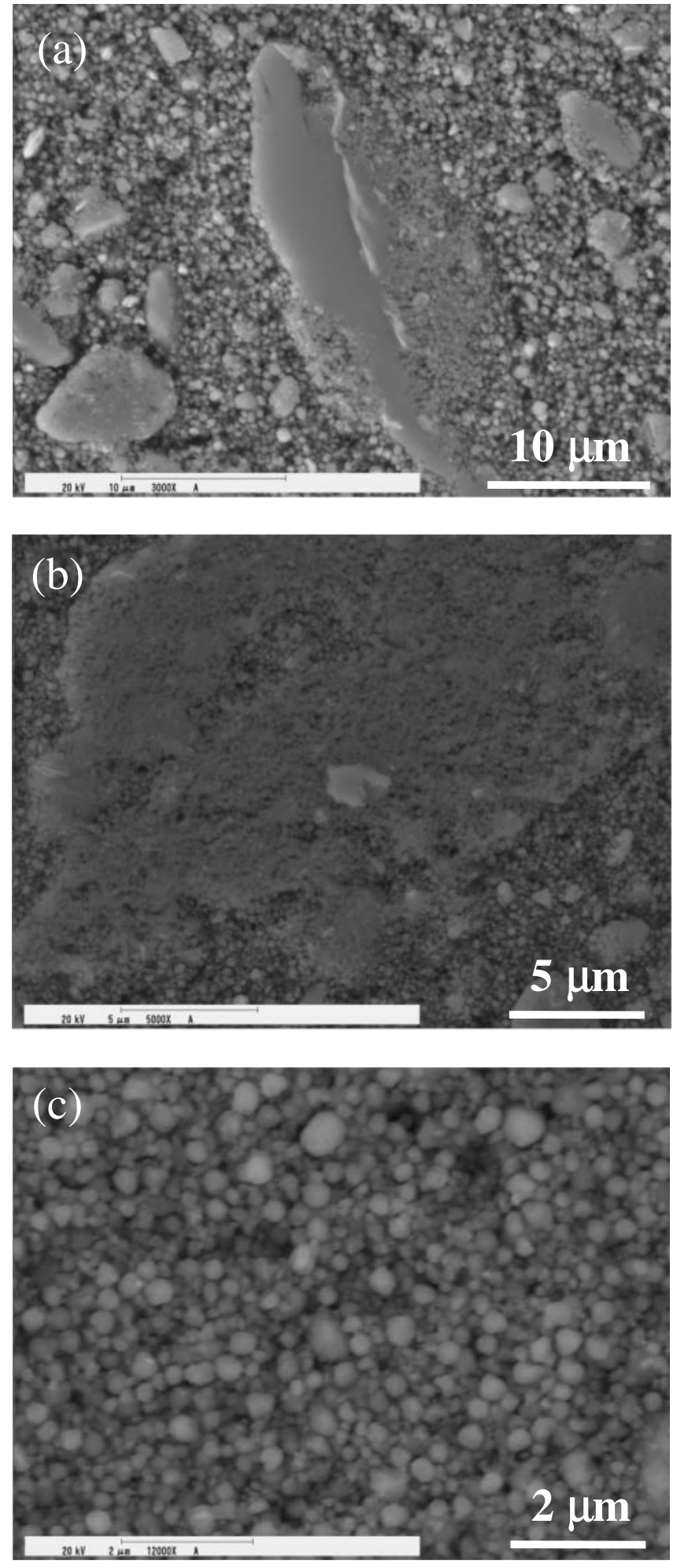

Fig. 3 SEM photograph of the powders for (a) $100 \mathrm{~h}$ milling time, (b) $200 \mathrm{~h}$ milling time and (c) $700 \mathrm{~h}$ milling time.

decreased with an increase in milling time. Those for titanium, molybdenum, nickel and carbon disappeared after $700,700,100$, and $8 \mathrm{~h}$ milling time, respectively.

The results of a TEM-EDS analysis of the powder after $700 \mathrm{~h}$ milling time are shown in Fig. 5. It is noted that fine grains, of about $5 \mathrm{~nm}$, were in the particles (from Fig. 5(a)). This size is in close agreement with that as calculated by Scherrer's formula. The diffraction pattern of the particle was a typical fcc Debye ring of polycrystalline structure (Fig. 5(b)). As a consequence of the diffraction pattern, the lattice constant was estimated to be $0.4315 \mathrm{~nm}$. This value is smaller than that for $\mathrm{TiC}(0.43274 \mathrm{~nm})$, but close. Therefore, the particles definitely had a $\mathrm{TiC}$ structure. It is confirmed from the result of EDS (Fig. 5(c)) that the compositional ratio for the particles was approximately the same as that for the starting powder. Although the particles contained molybdenum and nickel, there was no diffraction pattern, except for a TiC structure. It may be considered that these elements dissolved into a TiC structure and/or transformed into an amorphous phase. It has been reported that amorphization has been found in Ni-Ti systems by mechanical alloying. ${ }^{14)}$ It is also reported that a $\mathrm{Ni}$ solid solution has been transformed from a crystalline phase into an amorphous phase in Ti-C-Ni by ball milling. ${ }^{11)}$ As mentioned above, there were no peaks for Ni by XRD. It may be concluded that the Ni solid solution transformed the crystalline phase into an amorphous phase in Ti-Mo-Ni-C during ball milling.

The SEM photograph of the sintered compact is shown in Fig. 6. A narrow grain size distribution was obtained and the average grain size is about $500 \mathrm{~nm}$. It may be considered that these are attributed to nano-scale grain size of sufficient mixed powder. It is known that the core-rim structure of the hard phase shows a contrast between core and rim in SEM observation, ${ }^{13)}$ however, there was no contrast for the hard phase. It may be indicated that it consisted of a single phase.

The XRD patterns of the sintered compact and the milled powders are shown in Fig. 7. The peaks of nickel and TiC structure existed for the sintered compact. This may indicate that the nickel based amorphous phase was transformed into crystallization during the sintering process. The angles for the nickel peaks trended toward a lower angle. It is known that a $\mathrm{Ni}$ binder in $\mathrm{TiC}$ system cermets containing Mo has some amount of Ti and Mo. ${ }^{15)}$ Therefore, it is presumed that some Mo and Ti caused the shift of the nickel peak in this work. On the other hand, it is noted that the peak positions of TiC structure for the powder is almost the same as that for sintered compact, presuming that the chemical compositions of them are almost the same.

The results of TEM/EDS analysis of the sintered compact are shown in Fig. 8. As a consequence of the diffraction pattern, the lattice constant is $0.4315 \mathrm{~nm}$. This value is almost the same as that of powder, but smaller than the lattice constant of $\mathrm{TiC}(0.43274 \mathrm{~nm})$. From Fig. 8(c), the Mo content is about 33 mass\% for the center and the edge of the TiC structure grain. In addition, it is shown from Fig. 7 that the peak positions of $\mathrm{TiC}$ structure were the same for the powder and the sintered compact. Therefore, it is noted that the solution of molybdenum caused the difference of lattice for a $\mathrm{TiC}$ structure lower than that for $\mathrm{TiC}$, and the solution of molybdenum in $\mathrm{TiC}$ structure was caused by ball milling in powder, and the Mo/Ti ratio is about 3/7 in this work.

\section{Conclusions}

The microstructural evolution of (Ti,Mo)C-Ni powder by mechanical alloying pure titanium, nickel, carbon and molybdenum as a starting powder with a composition of TiC-20 $\mathrm{Mo}_{2} \mathrm{C}-20 \mathrm{Ni}$ in mass\% were investigated by X-ray 


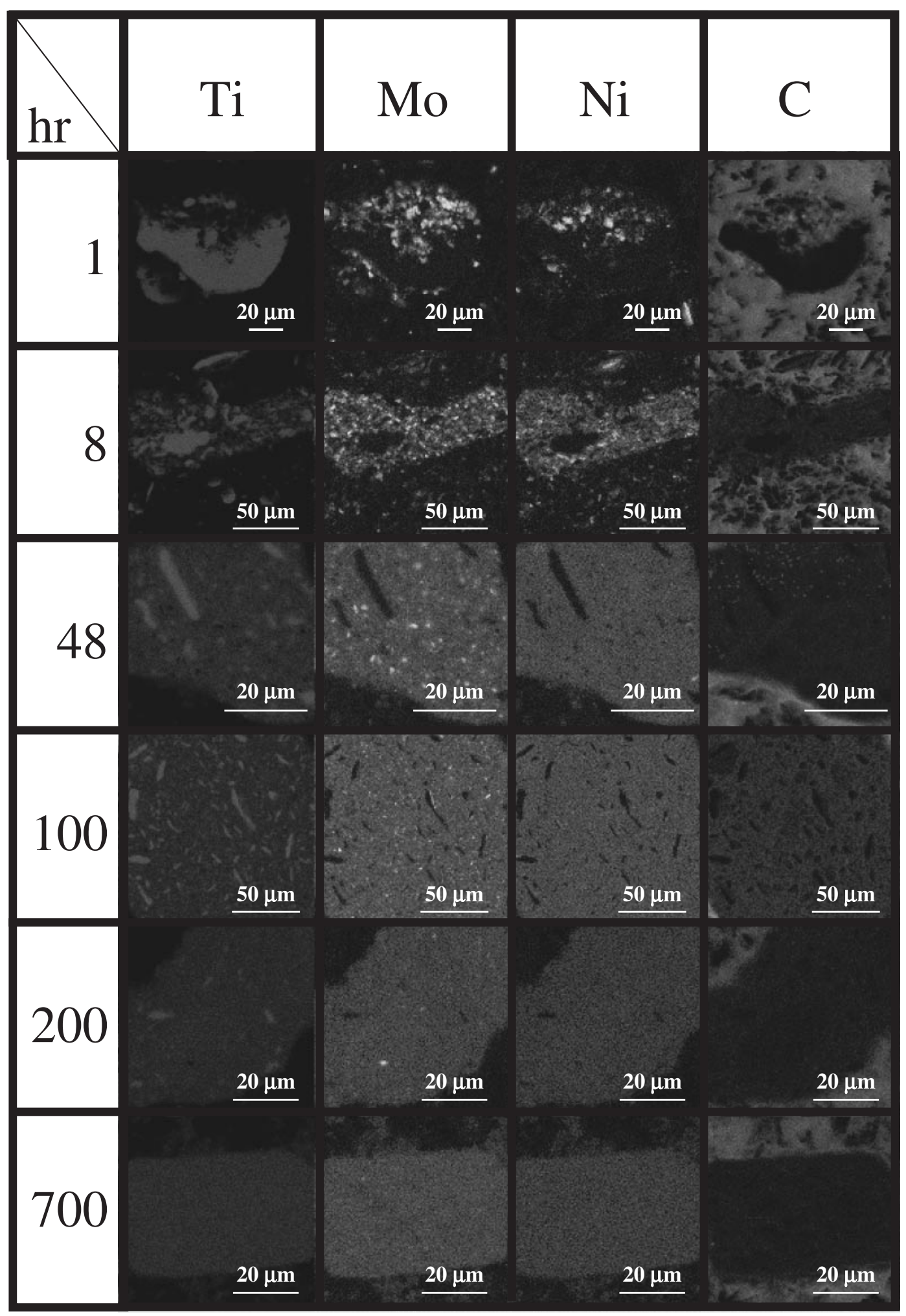

Fig. 4 EDS mapping images of the powders for various milling times.

diffraction (XRD) using $\mathrm{CuK} \alpha$ radiation, field emission scanning electron microscopy (FE-SEM) with energy-dispersive X-ray spectroscopy (EDS) and transmission electron microscopy (TEM) with EDS in detail. The results were as follows.

(1) The titanium, molybdenum, nickel and carbon peaks gradually became weaker with an increase in milling time, and disappeared after 200, 700, 100, and $8 \mathrm{~h}$ milling time, respectively. A TiC structure, which indicated a lower lattice constant than that for $\mathrm{TiC}$, appeared after $100 \mathrm{~h}$ milling time and there were only the peaks for the $\mathrm{TiC}$ structure after $700 \mathrm{~h}$ milling time.

(2) Sub-micrometers particles were produced by ball milling, and their ratio increased with an increase in milling time. The size of almost all particles was sub-micrometers after $700 \mathrm{~h}$ milling time. 


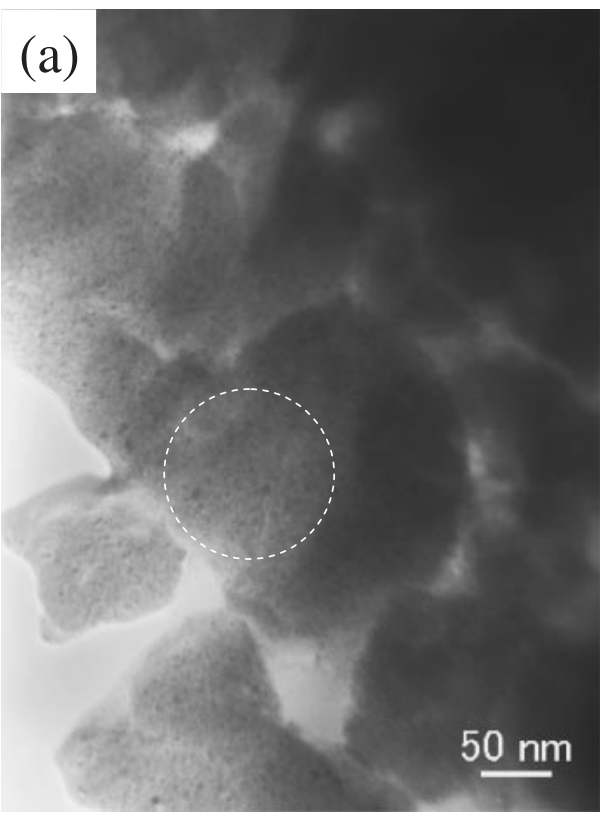

(b)

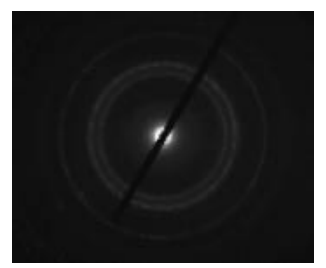

(c)

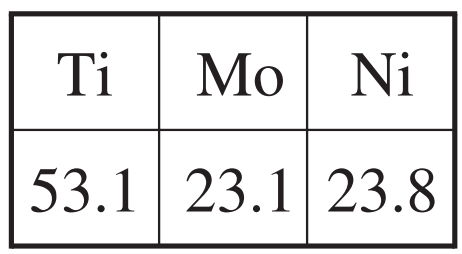

Fig. 5 TEM/EDS analysis of the powders for $700 \mathrm{~h}$ milling time. (a) bright-field image, (b) the selected area diffraction pattern and (c) EDS analysis (in weight). The circle with broken line indicate the area of (b) and (c).

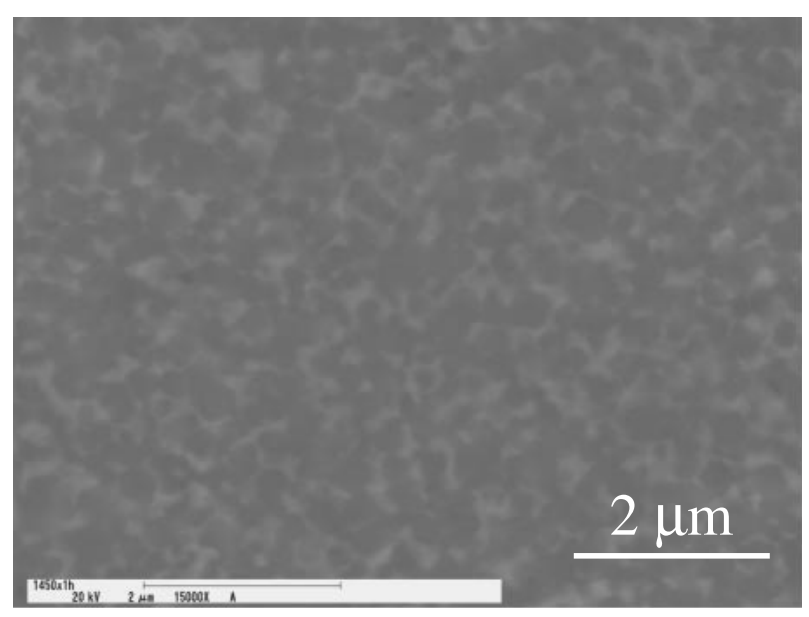

Fig. 6 SEM photograph of the sintered compact at $1723 \mathrm{~K}$ for $1 \mathrm{~h}$ by $700 \mathrm{~h}$ milling time.

(3) The high concentrated regions of each element in aggregate analyzed by EDS mapping decreased with increased milling time, and dissapeared after $700 \mathrm{~h}$ milling time for $\mathrm{Ti}, 700 \mathrm{~h}$ milling time for $\mathrm{Mo}, 100 \mathrm{~h}$ milling time for $\mathrm{Ni}$, and $8 \mathrm{~h}$ milling time for $\mathrm{C}$.

(4) The particles consisted of fine grains with a size of about $5 \mathrm{~nm}$. There was only TiC structure in SADP,

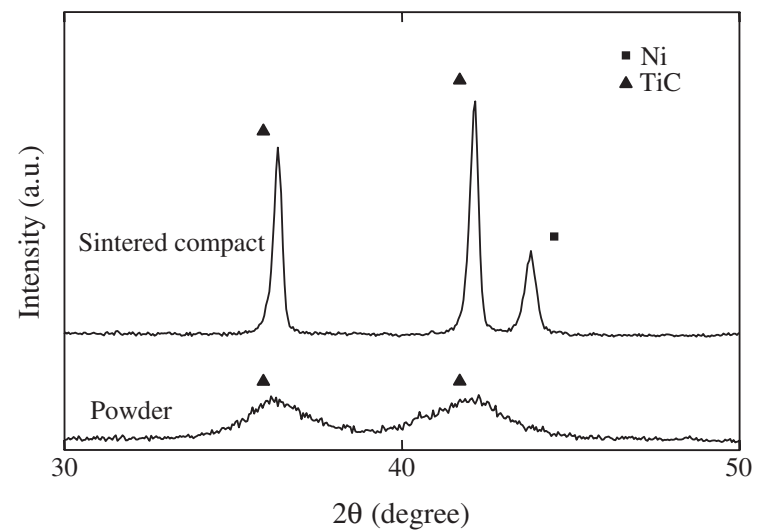

Fig. 7 XRD patterns for the sintered compact and the $700 \mathrm{~h}$ milled powder.

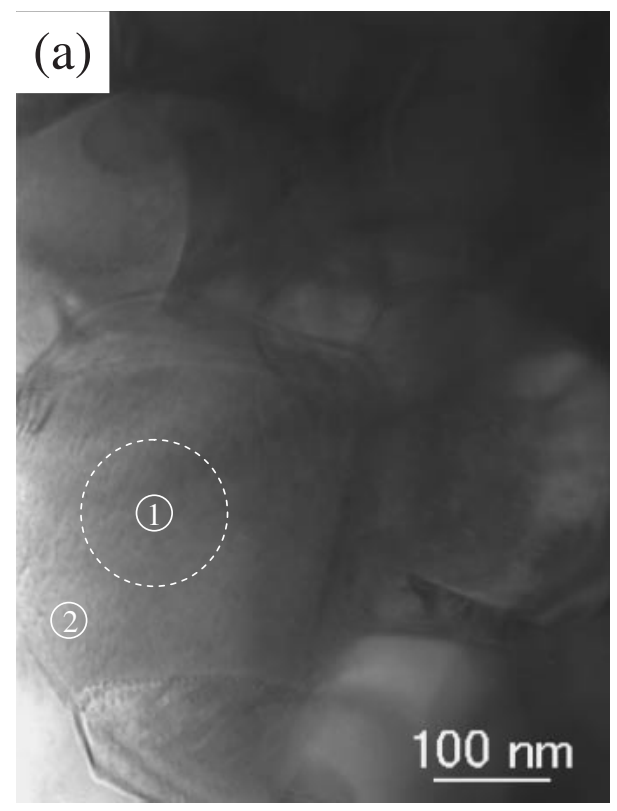

(b)

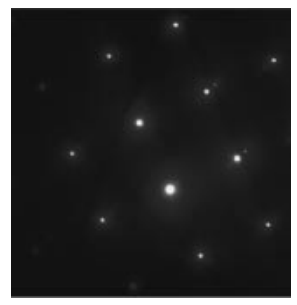

(c)

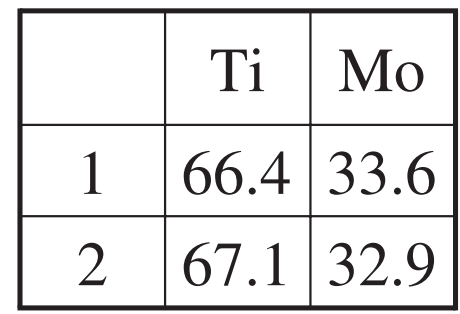

Fig. 8 TEM/EDS analysis of the sintered body. (a) bright-field image, (b) the selected area diffraction pattern for (001) plane and (c) EDS analysis (in weight). The circles with broken line and the solid line indicate the areas of (b) and (c), respectively.

although the chemical composition of the powder is approximately the same as the starting chemical component.

(5) When the lattice constant and chemical composition for the sintered compact is compared with those for the powder, the molybdenum is dissolved into the $\mathrm{TiC}$ structure and the $\mathrm{Mo} / \mathrm{Ti}$ ratio in $(\mathrm{Ti}, \mathrm{Mo}) \mathrm{C}$ was about $3 / 7$. 


\section{Acknowledgement}

The authors gratefully acknowledge the financial support by Project (P08023) of the New Energy and Industrial Technology Development Organization (NEDO).

\section{REFERENCES}

1) M. Humenik Jr and N. M. Parikh: J. Am. Ceram. Soc. 39 (1956) 60-63.

2) N. M. Parikh and M. Humenik Jr.: J. Am. Ceram. Soc. 40 (1957) 315320.

3) N. M. Parikh: J. Am. Ceram. Soc. 40 (1957) 335-339.

4) P. Ettmayer, H. Kolaska, W. Lengauer and K. Dreyer: Int. J. Refractory Metal \& Hard Materials 13 (1995) 343-351.

5) D. Mari, S. Bolognini, G. Feusier, T. Cutard, C. Verdon, T. Viatte and W. Benoit: Int. J. Refractory Metals \& Hard Materials 21 (2003) 37-46.
6) D. Mari, S. Bolognini, G. Feusier, T. Cutard, T. Viatte and W. Benoit: Int. J. Refractory Metals \& Hard Materials 21 (2003) 47-53.

7) N. Liu, Y. Xu, Z. Li, M. Chen, G.i Li and L. Zhang: Ceram. Int. 29 (2003) 919-925.

8) P. Feng, W. Xiong, L. Yu, Y. Zheng and Y. Xia: Int. J. Refractory Metals \& Hard Materials 22 (2004) 133-138.

9) J. Jung and S. Kang: Acta Mater. 52 (2004) 1379-1386.

10) J. C. LaSalvia, D. K. Kim and M. A. Meyers: Mater. Sci. Eng. A 206 (1996) 71-80.

11) C.-J. Choi: J. Mater. Proc. Technol. 104 (2000) 127-132.

12) Y. K. Kim, J.-H. Shim, Y. W. Cho, H.-S. Yang and J.-K. Park: Int. J. Refractory Metals \& Hard Materials 22 (2004) 193-196.

13) H. Suzuki, K. Hayashi and H. Matsubara: J. Japan Inst. Metals 22 (1983) 312-319 (in Japanese).

14) M. X. Quan, K. Y. Wang, T. D. Shen and J. T. Wang: J. Alloy. Compd. 194 (1993) 325-330.

15) H. Suzuki, K. Hayashi, H. Matsubara and K. Tokumoto: J. Jpn. Soc. Powder Powder Metall. 30 (1983) 106. (in Japanese) 